Max Koch, Hubert Buch-Hansen and Martin Fritz

\title{
Shifting Priorities in Degrowth Research: An Argument for the Centrality of
}

\section{Human Needs}

Draft 09.02.2017

\section{Introduction}

Economic growth is neither socially inclusive nor ecologically sustainable. While in the rich countries the unequal distribution of wealth has reached the levels of the nineteenth century (Piketty, 2014), the Earth's carrying capacity is being exceeded in relation to at least three planetary boundaries: climate change, the nitrogen cycle and biodiversity loss (Rockström et al., 2009). The corollary is that economy and society and the associated production and consumption norms can no longer be considered as a system operating in a theoretical vacuum. Significant theoretical and empirical efforts have been made to demonstrate how socially inclusive development could evolve within ecological limits and beyond growth (Daly, 1991; D'Alisa et al., 2014; Koch and Mont, 2016). An increasing number of researchers and activists call for a transition to a global steady-state economy (Koch, 2015) that would function within ecological boundaries. Although degrowth scholars generally accept that economic development in some form is required in the global South, the conventional development path - as in the North - is not advocated.

Less consensual, however, are estimations about how enjoyable or painful such a journey towards global environmental sustainability would be for the citizens of the rich countries. A particularly controversial topic is the issue of happiness or subjective well-being vis-à-vis objective welfare 
indicators. While a majority of degrowth scholars (e.g. Sekulova, 2014) appears to be confident that the transition to a global SSE would be accompanied by increases in both objective and subjective well-being scores, others are more careful (O’Neill, 2015; Fritz and Koch, 2016) and open up for the possibility that subjective well-being scores in the rich countries may (temporarily) go down if production and consumption patterns were to be brought in line with ecological limits. Judging by the historical genesis of 'degrowth' definitions the former position appears to have prevailed: In the declaration of the 2008 degrowth conference in Paris, degrowth was defined as a 'voluntary transition towards a just, participatory, and ecologically sustainable society', while the 'objectives' were 'to meet basic human needs and ensure a high quality of life ...' (Research and Degrowth, 2010: 523). While this original definition highlighted the centrality of human needs and did not presuppose a simultaneous rise in subjective well-being along the way, an often-cited passage by Schneider et al. (2010: 512) is much more straightforward. Here, 'degrowth' is understood to be, among other things, 'an equitable downscaling of production that increases human well-being and enhances ecological conditions at the local and global level, in the short and long term.' The latter definition also seems to have been behind the invitation text to the 2016 degrowth conference in Budapest, where 'degrowth' was defined as a 'downscaling of production and consumption that increases human well-being and enhances ecological conditions and equity on the planet'.

The question arises whether the degrowth research community should endorse this downscaling of production and consumption only if it at the same time increases or at least maintains wellbeing including in the short term. In this paper, we offer an argument for a return to the original Paris definition or, in other words, for a deprioritization of subjective well-being and, at the same time, a prioritization of human needs in degrowth research. It is structured as follows: The point 
of departure of the paper is existing empirical evidence on subjective well-being relative to scale and GDP/capita. We consider here both analyses of countries over time and cross-country comparisons. This is followed by a discussion of some methodological issues and theoretical shortcomings concerning the use of subjective well-being scores. These are the background for our plea for the centrality of objective welfare measures and, particularly, human needs within degrowth research. The next section identifies basic and intermediate human needs using the terminology offered by Doyal and Gough (1991) and outlines how this can be applied within the degrowth research agenda. Finally, we illustrate our argument for the centrality of human needs at the example of nutrition and argue that a needs-oriented degrowth agenda would be oriented at issues such as the following: What are the environmental impacts of different kinds of food production (conventional versus organic farming methods)? How do the different forms of production compare in terms of scale and the agricultural land-use required to feed all people? Do such scenarios suggest particular diets (e.g. vegetarian) over others (e.g. omnivorous ones)?

\section{Subjective well-being as a measure of welfare and degrowth}

The development and optimization of objective and subjective measurements of well-being in the social sciences has proceeded in concurrent and occasionally conflictive ways. Both have, of course, their respective merits and justifications. The improvement of the objective quality of life such as the supply of clean water, sufficient housing or the access to medical care is widely accepted as foremost goals in research and public policy-making. However, precisely which objective living conditions are relevant and to what degree they should be improved are far from being self-evident. This is why happiness researchers (Layard, 2011) suggest paying more attention to individual satisfaction with objective conditions. The debate around the Easterlin paradox (Easterlin, 1974; Easterlin et al., 2010) indeed demonstrates that the consideration of 
objective factors only is not sufficient when evaluating the quality of life of social groups. A problem with this view is that subjective satisfaction and well-being is in part the result of psychological and social adaptation processes that interfere with the happiness or subjective wellbeing gains that may be achieved through economic development measured in GDP per capita. Yet such complex processes are difficult to measure in large-scale and quantitative studies and would require long-term panel studies which are very expensive and accordingly rare. The alternative is qualitative in-depth research of small groups. Such research designs are, however, not statistically representative for larger populations.

Since degrowth research intends to provide knowledge in relation to global and local levels it depends to some extent on quantitative data on both objective and subjective well-being. In relation to the latter it is important to distinguish between two perspectives and measurements: individual-level data on subjective well-being of single countries over time and comparative country-level data on subjective well-being across countries. It seems that the majority of degrowth researchers have referred to and/or used data of the former kind (Alexander, 2012). Such data have repeatedly indicated that happiness and subjective well-being scores do not increase in parallel to GDP and income after rather modest levels. Indeed, in countries such as the USA happiness scores have remained at similar levels since the 1950s despite significant increases in GDP (Layard, 2011). ${ }^{1}$ Moreover, when interpreting these data, it is sometimes forgotten that while GDP can in principle increase infinitely, some of the rich countries (e.g. Denmark, where the cultural norm to present oneself as 'happy' is particularly pronounced) have

\footnotetext{
${ }^{1}$ Kahneman and Deaton (2010) distinguish between emotional wellbeing (also: affective wellbeing or hedonic wellbeing) and evaluative wellbeing (also: life satisfaction). While the former refers to the everyday feelings and emotions people experience, e.g. joy, sadness, stress etc., the latter is concerned with peoples' thoughts about their lives in general. The authors claim that this distinction may become increasingly important in relation to which subjective wellbeing measures may guide policy priorities.
} 
already reached comparatively high subjective well-being scores on a scale of 1 to 10 so that even higher scores are difficult to achieve. When taking the latter perspective and comparing subjective well-being levels across countries, however, one arrives at a somewhat different picture. Taking a global perspective, O’Neill (2015: 1223), for example, observes a 'correlation between biophysical scale and human well-being. Countries with a large per capita footprint tend to score highly on life satisfaction ..., while countries with a small per capita footprint tend to score poorly.' And in a recent comparison of 138 countries, Fritz and Koch (2016: 44) demonstrate that subjective well-being scores correlate with GDP per capita. The richest countries, which are at the same time the most unsustainable ones, score the highest in terms of subjective well-being. Hence, two things appear to apply at the same time: while happiness and subjective well-being scores in the rich countries do not increase further with GDP over time, cross-country comparisons demonstrate that poorer countries score much lower in subjective well-being than richer ones. While this may, in relation to the poorer countries, be in line with Easterlin's original finding that happiness depends more on how one fares compared with others than on the absolute level of affluence (Easterlin, 1974), it is unclear how subjective well-being scores would develop in the rich countries during an economic contraction.

Taking a global perspective is plausible because major environmental issues such as climate change have a global dimension in that it does not matter from what locality on the planet greenhouse gases, for example, are emitted. Fritz and Koch (2016), who divided 138 countries in five groups according to GDP per capita ('poor', 'developing', 'emerging', 'rich' and 'overdeveloped' countries), further found that only the poorest countries can currently be seen as 
existing within environmental limits. ${ }^{2}$ The others would need to 'degrow' in terms of their matter and energy throughput (most of them significantly), if these limits are to be respected. Embarking on the degrowth trajectories needed to bring about a 'global steady state economy' - a world economy that functions within environmental limits thereby avoiding catastrophic climate change and other environmental threats - is in itself an enormous challenge (Buch-Hansen, 2014). It is aggravated by the fact that both objective and subjective quality of life indicators but also $\mathrm{CO} 2$ emissions and ecological footprints have hitherto increased with GDP per capita. Given that the currently richest countries would need to make the biggest contribution en route to a global steady-state economy in a rather short period of time, we would not exclude by definition that subjective well-being scores in the rich countries may (temporarily) go down. From an ethical research perspective we consider it important to be as honest and 'objective' as possible about the prospect that such a transition cannot be done without serious changes in - and limitations of the comfortable aspects of the Western 'way of life'. Many of these - related for example to meat consumption and the use of airplanes and electronic gadgets with a short life-span - have the potential of leading to decreases in subjective well-being scores, at least in the short-term. However, we would still argue that such a transition is necessary because a business-as-usual scenario, where no measures towards the establishment of a global steady-state economy are taken, would most likely be accompanied by continuous decreases in subjective well-being everywhere in the longer term due to the massive deterioration of living conditions in a 'broken world' characterized by climate change and other dimensions of the environmental crisis. While we certainly would like to see as many inhabitants of the Earth as happy as possible, the enormity of the task that an adjustment of the global political economy to natural requirements would

\footnotetext{
2 This study was based on comparative aggregated country-level data that do not allow for the consideration of transnational inequality as emphasized in transnational class approaches.
} 
entail may temporarily not allow more than the satisfaction of basic human needs to which we turn in the next section.

In the remaining part of this section we would like to mention and briefly discuss some methodological issues with and theoretical shortcomings of the concept of happiness and subjective well-being that, in our view, likewise suggest their deprioritization in degrowth research. When measuring subjective well-being, people from very different cultures are usually asked how happy or satisfied they perceive themselves on a scale from 1 to 10 . On top of the adaptation problem (see above) there is evidence of cultural bias. When national values of individualism are correlated with reported well-being, cultures representing a 'modesty bias' (Gough, 2015), as in some East-Asian countries, report lower well-being scores than some Western countries where the promotion of 'happiness' is much more part of the way of life. Though such problems may be to some extent controlled for when comparing well-being within societies, we agree with Gough (2015: 5) that 'they fundamentally undermine the ability of "happiness" to provide a measure of well-being across cultures and times.'

Critical management and industrial relations approaches likewise raise doubts in the functionality of 'happiness' as a universal measurement for human well-being. This may be illustrated by way of a comparison of the Fordist worker and the modern, entrepreneurial and self-reflective employee. Manual workers in Fordism were largely reduced to carrying out simple and repetitive tasks. The rhythm of the machinery dictated the working day which could drive one, in extreme cases such as in Charley Chaplin's film Modern Times, crazy. However, the difference between the working day and 'free time' was obvious to everybody and not even Frederick Taylor would have expected his workers to feel 'happy' about their work situation. Organized labour accepted 
his 'scientific' management methods because of increased real wages, holidays, sickness and oldage insurance funds etc., and not because of a subjective identification with the company on part of the workers. In fact there was a clear consciousness about the authoritarian nature of the factory regime and the corresponding power relations between management and labour. When the limits of Taylorism to further raise productivity became obvious, management philosophies and the associated capital-labour relations began to explore new paths and patterns many of which included a much higher regard for the 'subjective element' of the production process. In modern 'flat' hierarchies workers are more often part of a 'team', where their voice is heard if it serves profitability. This may often lead to greater amounts of subjective identification with the company's goals. A 'good employee' is one that makes the company's fate his or her own, is happy when the company fares well and unhappy when not, and does not insist on a strict separation of work and free time. Consequently, authors such William Davies (2015) suggest that our happiness depends to a significant extent on the successfulness of our performance in the capitalist division of labour. Since in current 'teamwork' arrangements power relations are less visible than in the factory regimes of the post-war period, these make, in Foucauldian terms, for a much better 'economy of power' (Foucault, 1977) than the obviously authoritarian Fordist industrial relations.

Hence, the emphasis on 'subjectivity' and 'happiness' is an important element of contemporary work life where workers are not only expected to sell their capability to work but, increasingly, their hearts and minds too. And indeed, according to Oswald et al. (2008) workers are more productive when they feel happy, apparently by as much an additional 12 percent of output. Considering that one's individual well-being owes so much to one's identification with the position one has in the division of labour - which allows one to be a legitimate consumer as well 
- it is surprising that happiness theorists write so little about the many who lack this kind of success. Linked to the chance to succeed individually is the risk to fail. Judging by the massive spread of mental health disorders in Western countries ${ }^{3}$, the flip side of the 'happiness industry' (Davies), which puts an immense pressure on individuals to prosper while mystifying structural power relations that decrease the likelihood of doing so, appears to be the rise of a 'depression industry', which generates sustained profits from the fact that people think of themselves as 'failures' - in many cases just because the benchmarks the company set for them could not be met. If 'degrowth' involves a fundamental shift away from contemporary industrial relations, growth-critical researchers should not uncritically accept the subjective welfare indicators that partly originate in the management approaches from which these relations evolved. In contrast to subjective measures of welfare, objective measures have the advantage of being more transparent, thereby facilitating the recognition and - ultimately - overcoming of structural power relations.

\section{An 'objective' measure of welfare: Human needs}

Subjective conceptions of well-being have produced interesting results but share a range of problems that undermine their ability to serve as universal measures of welfare. Especially since adaptation - the adjustment of expectations to reality including the upgrading of one's expectations in terms of material consumption - appears to be pervasive, 'happiness' and subjective well-being are ill-positioned to serve as yardstick for a degrowth transition that involves the downscaling of objective indicators such as the global matter and energy throughput. In this section, we assess a methodological alternative: the human needs approach exemplifying

\footnotetext{
${ }^{3}$ According to Davies (2015: 107), 'over a third of European and American adults are suffering from some form of mental health problem'.
} 
an 'objective' welfare measure. Whilst growth-critical scholars have not studied the issue of human needs in depth (see, for an exception to this rule, Koch and Buch-Hansen, 2016), it has been noted that degrowth 'is about reducing the energy and material flows while still fulfilling basic and growing human needs such as food, health, education and housing' (Boillat et al., 2012: 600). In contrast to the concepts of preference satisfaction, 'wants' - regarded as 'insatiable' in neoclassical theorising - and subjective well-being, 'needs' are by definition few and limited. Hence, while preference satisfaction, wants and subjective well-being correspond with an economy geared at unlimited monetary growth and exchange value, the latter is in principle compatible with an economy based on stable matter and energy throughput and the provision of use values serving as basic needs satisfiers. Human needs further differ from wants, preferences and happiness in that they are non-negotiable (Gasper, 1996: 6) and applicable universally to all humans now and in the future (Max-Neef, 1991). They do not vary over time and across cultures but according to the ways in which a specific culture at a particular point in time attempts to satisfy them.

The origins of the 'basic needs development strategy' go back to the 1970s and the World Employment Program of the International Labour Organization. This was reflected in the 'ecodevelopment' movement which emphasized the satisfaction of basic needs (rather than GDP growth) as the main focus of public policies in the South. While human needs theories can be traced back to Aristotle, the two most systematic approaches have been tabled by Max-Neef (1991) and Doyal and Gough (1991). The former understands needs as interrelated, interactive and non-hierarchical system and proposes a two-dimensional typology with nine 'axiological needs' (subsistence, protection, affection, understanding, participation, identity, idleness, creation and freedom). Doyal and Gough's approach is hierarchical, moving from universal goals, through 
basic needs to intermediate needs. We consider the latter approach particularly relevant for degrowth and steady-state research due to the centrality of the notion of environmental limits that define different levels, especially at the lowest level, at which human needs - understood as a 'minimally decent life' - can be satisfied (Gough, 2015).

Doyal and Gough accept and start from Kant's classical argument that individuals must have both the physical and mental capacity to act and be responsible. 'Serious harm' of some objective kind will result if the 'pursuit of one's vision of the good, whatever that vision is' (Doyal and Gough, 1991: 50) is severely undermined. Basic needs are then 'universalisable preconditions for nonimpaired participation in any form of life' (Gough, 2015: 7). The two authors go on to identify health and personal autonomy as the most basic human needs. Physical and mental health are absolute preconditions for pursuing goals, whatever these goals are, and completing a range of practical tasks in any society. As Assiter and Noonan (2007: 180) argue, a 'combination of traditional and biomedical models' can provide a trans-cultural baseline measure of physical and mental health - beyond the non-generalizable healthcare and welfare systems that developed in OECD countries in the post-war context. 'Autonomy' is defined as 'the ability to make informed choices about what should be done and how to go about doing it' (Doyal and Gough, 1991: 53). Irrespective of societal contexts, the three key variables for individual autonomy are cognitive and emotional capacity, cultural understanding (the acquisition of language and other social skills) and autonomy of agency (a range of opportunities to actually undertake socially significant activities). This opens up for the issue of what sort of institutional arrangement does foster the two basic needs and what sort prevents it. A similar discussion can already be found in Fromm (1956). 
Doyal and Gough's conceptual bridge between needs and needs satisfiers is the introduction of 'universal satisfier characteristics'. Accordingly, there are general features of need satisfiers applicable to all cultures at all times. These are referred to as 'intermediate needs' and grouped in eleven categories, whereby the first five contribute to physical and mental health and the last six to autonomy (Figure 1): adequate nutritional food and water, protective housing, non-hazardous work environment, non-hazardous physical environment, appropriate healthcare; and security in childhood, significant primary relationships, physical security, economic security, safe birth control and child-bearing, as well as basic and adequate education. Though there are general characteristics of needs satisfiers, their kind and amounts are nevertheless relative and to a huge extent dependent on a range of cultural factors. These include the available and applicable scientific knowledge, but also comparative anthropological cultures, sub-cultures and political systems. 
Figure 1: Basic and universal intermediate needs (Doyal and Gough, 1991; Gough, 2015)

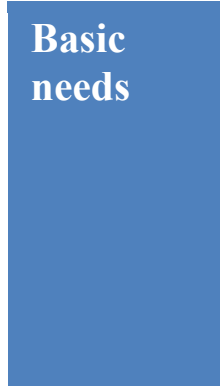

Physical

and mental health

\section{Critical} autonomy (ability to make informed choices)

\section{Universal intermediate needs}

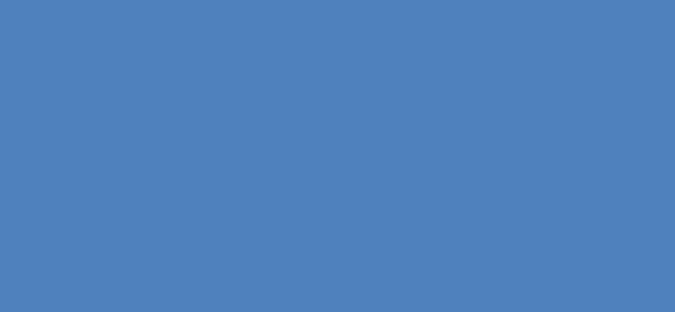

Adequate nutritional food and water Adequate protective housing Non-hazardous work environment Non-hazardous physical environment Appropriate health care

$$
\begin{aligned}
& \text { Security in childhood } \\
& \text { Significant primary relationships } \\
& \text { Physical security } \\
& \text { Economic security } \\
& \text { Safe birth control and child-bearing } \\
& \text { Basic education }
\end{aligned}
$$

\section{Culturally, socially and locally} specific satisfiers

Ecological limits and planetary boundaries are seriously considered in Doyal and Gough's approach. This is obvious in their application of the 'minimum optimorum' or 'minopt' concept to define critical thresholds of intermediate needs, whereby the relationship between the minimum quantity of any given intermediate need-satisfaction and the optimum level of basic need satisfaction is seen as asymptotic: 'Additional increments of a satisfier characteristic generating decreasing increments of basic need satisfaction until at the minopt point no additional benefit is derived' (Gough, 2014: 378). Critical thresholds for the universal provision of human needs (and wants) or for a 'minimally decent life' are to be constantly (re-)defined in light of the advancement of scientific knowledge. For this 'auditing process' the natural sciences but also heterodox economics and other branches of the social sciences could play important parts. These 
disciplines would however need to be integrated in relation to the satisfaction of human needs within a global steady-state economy.

It follows from Doyal and Gough's parsimonious definition of basic human needs that these will be the same for future people as those of the present. And the same categories of universal satisfier characteristics will apply: 'Future people will have needs for affiliation, cognitive and emotional expression, understanding and critical thought.' (Gough, 2015: 13) This has repercussions for the structure of the present economy. In O'Neill's (2011: 33) words, 'each generation needs to pass down the conditions for livelihood and good health, for social affiliation, for the development of capacities for practical reasoning, for engaging with the wider natural world and so on.' Even though the present generation may be largely ignorant about the 'detailed nature and quantum need satisfiers that future peoples in future contexts will require' (Gough, 2015: 14), Doyal and Gough (1991: 230-236) nevertheless stress that all economic systems would need to be assessed according to their ability to produce enough appropriate need satisfiers. However, due to climate change and ecological overshoot, one should not rule out the possibility that less than the 'optimal generalizable satisfaction of basic needs' can actually be achieved (Gough, 2014: 378). Society would then need to find ways to debate possible offsets between the satisfaction of the needs of current and future generations.

Whether it is possible to provide satisfaction of basic and intermediate human needs on a global scale, and the extent to which more than basic needs (and wants) can be provided on a finite planet without overshooting ecological limits, are timely issues and questions for empirical and comparative research. Such research would address Doyal and Gough's eleven intermediary needs and produce knowledge on how to best satisfy them in a world characterized by constraint 
and ecological crisis and without compromizing the needs of future generations. It could conclude with suggesting principles of 'policy auditing' in relation to the eleven intermediary needs. The limitations and fallibility of (social) scientific knowledge should always be kept in mind, but in principle academic research can assist activists by sketching out the extents to which the eleven intermediary human needs can be met universally and intergenerationally. In the next section, we present research findings on food production to tentatively illustrate the lines along which existing knowledge can inform considerations regarding the possibility of satisfying the global population's need for nutrition in an environmentally sustainable manner.

\section{Satisfying the global need for food}

Food (and clean water) belongs in Doyal and Gough's terminology to the 'universal satisfier characteristics' or intermediary needs: "those "inputs" which, according to the best available knowledge, contribute positively to the "output" of individual health and autonomy in all cultures' (Doyal and Gough, 1991: 191). To avoid becoming physically ill, people must live in a 'healthy environment and must have access to a range of goods and services of sufficient quantity and quality.' (Doyal and Gough, 1991: 191) Hence, any intermediate need in relation to the basic need of physical health such as adequate nutrition will have a 'material base which will be identifiable within the terms of biomedical understanding.' (Doyal and Gough, 1991: 191) The current food production system is to a large extent part of the growth-based economic system and is overall extremely productive. However, although enough is being produced to satisfy the global population's basic need for food, 795 million people suffer from hunger (FAO, 2015: 4). Aside from the problem of an inequitable distribution of food, there is the equally fundamental problem that the industrialized form of agriculture, which has become conventional throughout the rich part of the world, is inherently unsustainable, causing profound damage to the 
environment. Heavily reliant on external inputs in the form of oil, electricity, machinery, chemical fertilizers, pesticides and other non-organic inputs, it for instance results in 'increased soil erosion, surface and groundwater contamination, release of greenhouse gasses, increased pest resistance, and loss of biodiversity' (Badgley et al., 2007).

A key feature of a steady-state economy is that the economy is characterized by a minimum level of throughput. 'Throughput' refers to the 'flows of matter and energy from the first stage of production' to the 'last stage of consumption' (Daly, 1991: 17). Conventional agriculture is not compatible with a steady-state economy as it entails a comparatively high throughput level. Calculating the energy consumption of the Spanish agri-food system in 2000, Amate and de Molina (2013: 30) find that 'for each unit of energy available in the form of food, 6 units of energy have been consumed in its production, distribution, transportation and preparation'. Agrarian production accounts for one third of this massive energy waste, owing mainly to the consumption of nitrogen and the import of grains from overseas, whereas transportation is found to be the second largest source of the system's energy consumption.

Unlike those who see further investments in biotechnology and other green innovations as the solution to the unsustainability of conventional agriculture, growth-critical scholars argue in favour of altogether different forms of agriculture. More concretely, such scholars have frequently suggested that organic/agro-ecological food production is desirable and necessary (e.g., Boonstra and Joosee, 2013; Kallis, 2011). This type of agriculture integrates ecological processes into farming practices instead of relying on fertilizers, pesticides or genetic modifications of organisms (see Gomiero et al., 2011 and Wezel et al., 2014: 3 for research reviews on the performance of organic agriculture). Organic agriculture does not use synthetic 
nitrogen fertilizer, which is responsible for $75 \%$ of all $\mathrm{CO} 2$ emissions in conventional farming (Haas et al., 1995), uses up to 75\% less fossil fuels (LaSalle and Hepperly, 2008: 4) and produces higher rates of soil carbon (instead of emitting it to the atmosphere as in conventional farming). Hence, it emits considerably less CO2/greenhouse gases than conventional agriculture (Figure 2). In terms of labour input organic farming is far less efficient than conventional agriculture. While this is usually considered an invalidating argument against organic farming, the possibility that more people may become involved in small-scale and sustainable food production may actually be welcomed from a degrowth perspective. Indeed, instead of huge farms growing single crops on a massive scale (monoculture) and in environmentally unsustainable ways, growth-critics envision a system where smaller and slower organic farms produce food in a sustainable manner. Gomiero et al. (2011: 114) add that an organic agriculture would offer 'great potential to generate green jobs and revitalize rural areas' via a promotion of a 'green economy and paying farmers for environmental services'. 
Figure 2: Organic versus conventional agriculture (in percent)

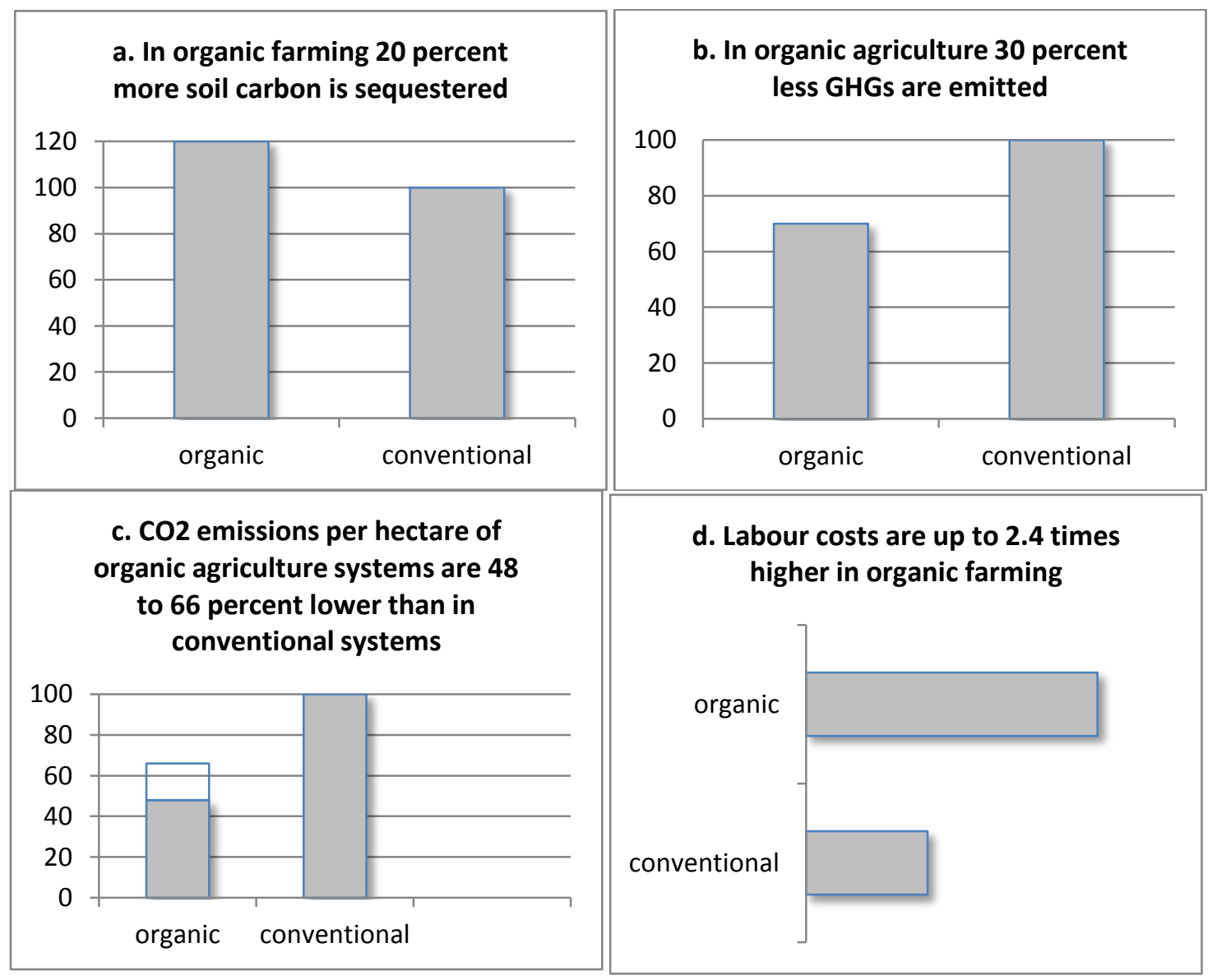

Sources: [a] Soil Association (2009); [b] Pimentel et al. (2005); [c] FAO (2002); [d] Matulla et al. (2003)

Organic farming is on the rise, but is still a marginal phenomenon in most parts of the world. For instance, the organic area only takes up $5.4 \%$ of Europe's total utilized agricultural area (European Commission, 2013). An interesting exception to this rule is Cuba which constitutes one of the few countries where both $\mathrm{CO} 2$ emissions per capita and the country's percentage of global CO2 emissions decreased between 1973 and 2005 (Koch, 2012: 133). Focusing on the Cuban experience with agroecology, Boillat et al. (2012: 601) call it 'today's largest real-life experience of agroecological "degrowth"'. The experience began in 1989, prior to which Cuba 
had a highly industrialized agricultural sector. The collapse of the Soviet Union and the US embargo resulted in reduced imports of for instance agrochemicals and industrial equipment. The situation forced the government to initiate a shift towards a system where more goods were produced within the country and where agriculture required fewer external inputs. The result was the emergence of a very large number of small and middle-sized organic/agroecological farms, worker-owned cooperatives and farmer's market. The scale of the shift was unprecedented in that it occurred throughout the entire island. Boillat et al. interpret this shift in terms of 'degrowth' because high standards of education and health were preserved while the environmental impact of the agricultural sector was drastically reduced (2012: 603). Yet they also note that there are still major problems. For instance, Cuba is still forced to import food because not enough food is being produced within the country, while the amount of agricultural production stagnated since 2004 (2012: 604).

In 1975, Georgescu-Roegen (1975: 378) wrote that 'mankind should gradually lower its population to a level that could be adequately fed only by organic agriculture'. Since then, the world population has increased from 4 billion to 7.2 billion people - and is currently projected to reach 9.6 billion in 2050 (Gerland, 2014). According to some estimates, it will only be possible to feed this number of people, if global food production grows by a staggering $70 \%$ between 2005 2007 and 2050 (FAO, 2011: 42). Given developments thus far - and given future projections - it is not surprising that a major theme in research on food production is whether it is at all possible to feed the global population with organically produced food without expanding the agricultural land base significantly. Such an expansion would involve a further conversion of ecosystems to agricultural land and is thus by no means desirable from an environmental sustainability perspective. 
The findings of such research vary. Badgley et al. (2007) suggest that organic yields were on par with, and in some cases exceeded, yields from conventional farming. They estimate that it will be possible to produce enough food by means of organic methods to sustain the current global population - and possibly a larger population - without expanding the existing agricultural land base. Other studies have contested these findings, questioning the data on which they were based. Seufert et al. (2012) examine the yield performance of conventional and organic farms globally and find that overall organic yields are $25 \%$ lower than conventional ones. For some crop types the gap was lower, for others it was higher. A subsequent study by Poniso et al. (2014), which applied a larger meta-dataset than that of Seufert et al., concludes that organic yields are overall merely $19.2 \%$ lower than conventional ones (Figure 2).

Figure 3: Yields in organic versus conventional agriculture (in percent)

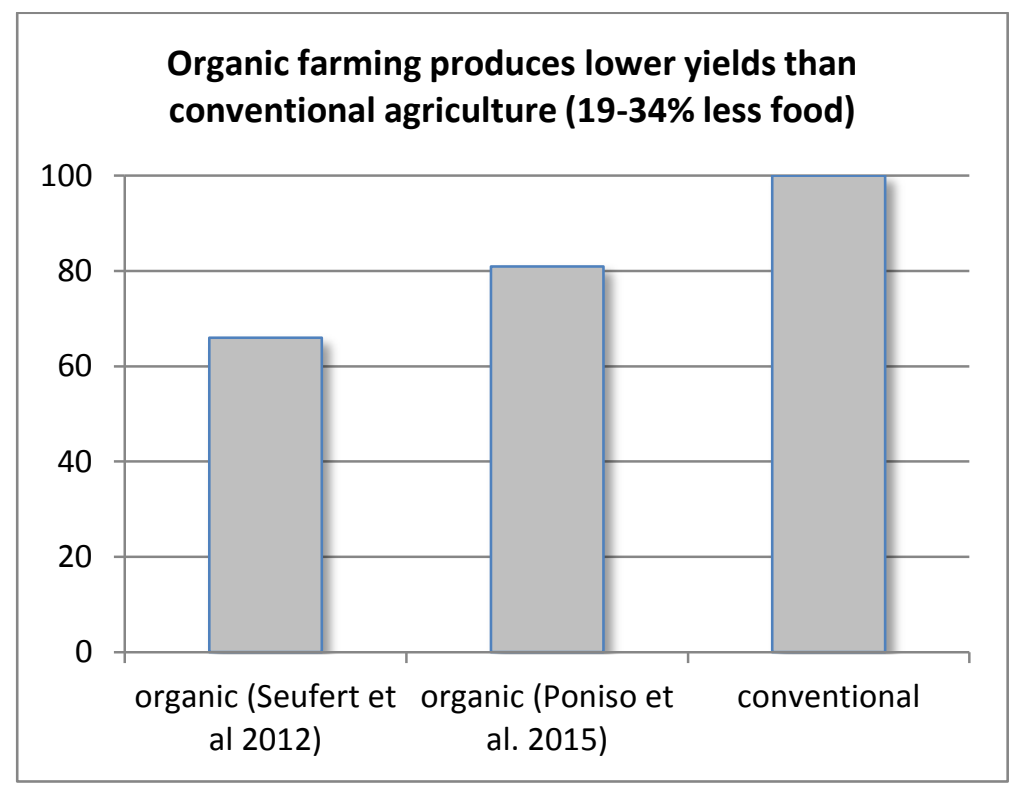


Given such findings it does not seem possible to satisfy the need for food on a global level if all food was produced organically. Yet this conclusion presupposes that the content of food production stays the same. The kind of food that is being produced is crucial inasmuch as the ecological footprints of different food types vary enormously. Currently food production for a meat-based diet takes up a sizeable amount of land. For instance, The World Watch Institute (2004) has noted that while 56 million acres of U.S. land produce hay for livestock, only 4 million acres produce vegetables for human consumption. Wirsenius et al. (2010) find that with a $25 \%$ decrease in meat consumption in the world's rich countries, combined with a 15-20\% decrease in the retail and household food wastage rate, land use in these countries would decrease by around 15\%. That global meat-production has severe environmental downsides is also documented in a meta-study by Tilman and Clark (2014). Among other things it shows that greenhouse gas emissions resulting from a vegetarian diet (white and light grey bars in Figure 4) are much lower than those resulting from diets containing fish or meat (dark grey and black bars). 
Figure 4: Food types and $\mathrm{CO} 2$ emissions

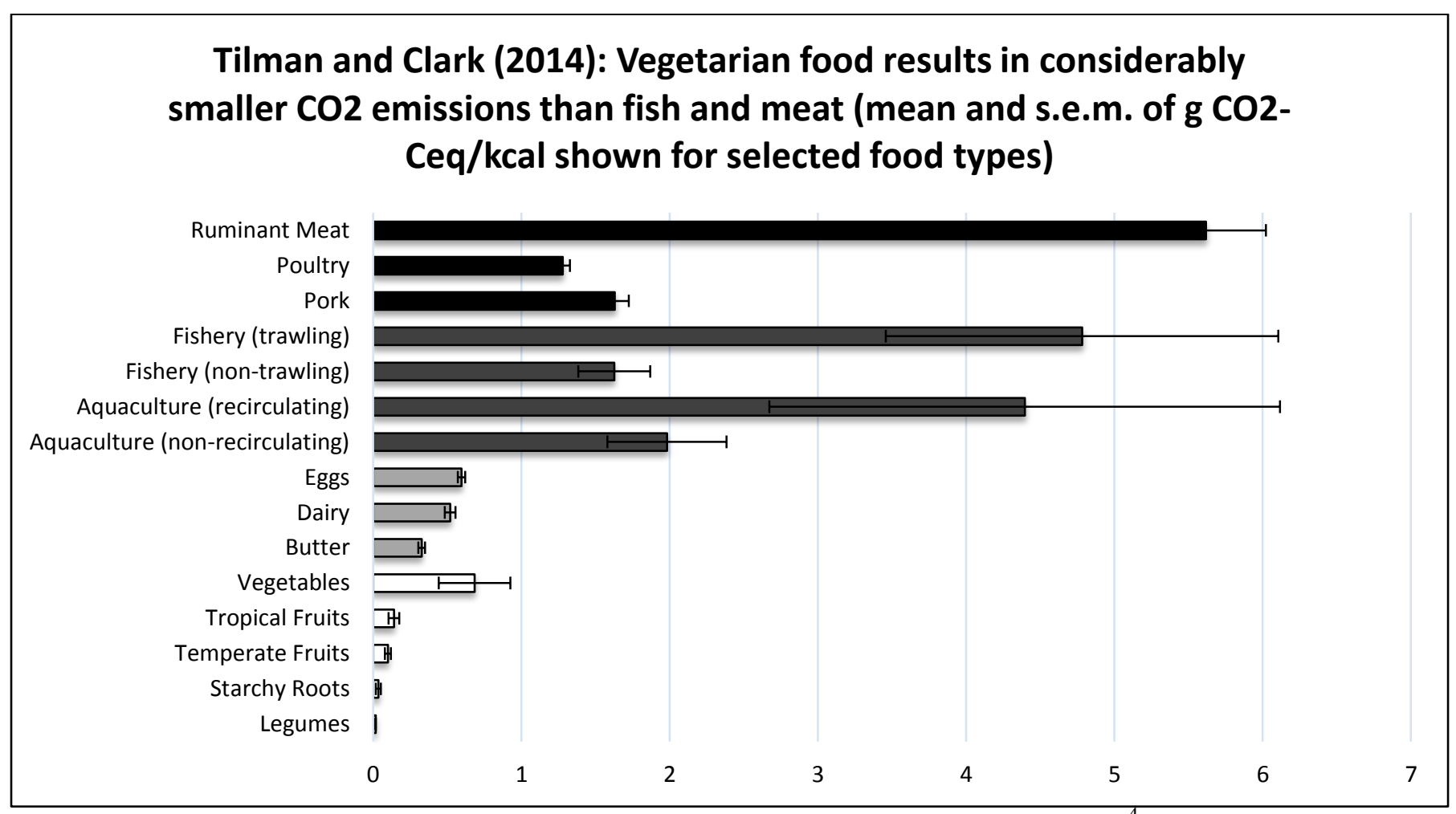

Source: Calculated from supplementary data provided by Tilman and Clark (2014). ${ }^{4}$

In this context, it is also worth noting that the aforementioned study of the Spanish agri-food system finds that the types of food that require the most energy for production and transport are at the same time the products that require the most energy (electricity or gas) for their preparation. Cooking meat products can result in the consumption of up to 70 times more energy than cooking vegetables. Against this background Amate and de Molina (2013: 32) reach the following conclusion, which resonates with the other findings presented above:

\footnotetext{
4 'Recirculating aquaculture' uses different treatments such as filtration and oxygenation to keep the water clean and healthy for fish in situations where water exchange is limited. Material and energy costs of this type of fish production are much higher than in the case of aquaculture where no such additional treatments are needed ('nonrecirculating').
} 
'We think that only a shift towards organic farming and corresponding changes in consumption patterns can contribute to substantial reductions of resource use in the food system and to sustainable de-growth. The way in which it can be achieved, even improving the quality of what we eat and without reducing agrarian income and employment, is to switch to organic farming, and to change over to a more vegetarian diet, with the emphasis on seasonal products produced locally.'

To our knowledge, existing research on food production does not provide clear answers to the question of whether the entire global population's need for food (now and in the future) could be satisfied with organic-vegetarian food. It is evident, though, that a vegetarian diet is not only more sustainable than diets that include meat, it can also feed a far larger population. In our view, the example of food production serves to illustrate why the satisfaction of basic needs is a more realistic degrowth objective than aspirations to increase well-being. People eat meat and fish to satisfy their preferences or wants, while cultural and social factors contribute to sustain this behavioural pattern. Depriving people who currently eat meat and fish as they please from that ability is very likely to affect their subjective well-being negatively, at least for a period of time. Yet considering the research findings presented in this section, seen from a degrowth perspective it is necessary that diets are changed.

\section{Discussion and conclusions}

The status of subjective welfare measures such as happiness or subjective well-being within degrowth research is controversial. Despite the fact that a majority of growth-critical scholars is confident that a downscaling of production and consumption patterns - on the necessity of which all degrowth researchers agree - would be accompanied by increases in subjective well-being 
scores in the short- and long-term, we have here pleaded for a deprioritization of 'happiness' and 'subjective well-being' within degrowth research. We have highlighted two main reasons for this. First and maybe most importantly, the empirical evidence for the link between GDP/capita and subjective well-being is far from being clear-cut. While data for one country over time suggest a flattening of the happiness curve relative to GDP growth, cross country comparisons reveal that the richest and most environmentally unsustainable countries are also the 'happiest'. Second, there are methodological issues and theoretical shortcomings that question the ability of 'happiness' to provide a measure of well-being across countries and times. Here, we have pointed to the issue of adaptability. A reduction and limitation in the use of 'positional goods' (Hirsch, 1976) such as cellphones, flights, cars or meat, which would be necessary in the transition to a global steady-state economy, is unlikely to be accompanied by short-term increases in subjective well-being in the rich countries. In addition, 'happiness' as a general societal objective is questionable, where it helps promote profits - and in consequence: economic growth - and disguise structural relationships of inequality and domination, especially within the work sphere. This may in fact partially explain why neoclassic economists such as Richard Layard embrace the concept.

At the example of food we have illustrated why, in our view, degrowth should rather aspire to the satisfaction of basic human needs than to increased subjective well-being. We reviewed recent research on the environmental impacts of different diets and different kinds of food production and on how these forms compare in terms of scale and land-use. The key findings are that (1) conventional agriculture is grossly unsustainable; (2) the yields of organic agriculture are lower than those of conventional agriculture and (3) a vegetarian diet has a far smaller ecological footprint than diets containing fish and meat. Taken together these findings indicate that if the 
global population's need for food is to be satisfied in an environmentally sustainable manner, a transition to a more vegetarian diet is required. Such a transition may well, however, come at the cost of decreased subjective well-being on part of those who have become accustomed to an omnivorous diet, at least in the short term. To be sure, food is only one of several intermediate human needs, and as such a counter to our argument could be that degrowth transitions might enable the satisfaction of other needs to an extent that the negative effects on subjective wellbeing of dietary change are offset. However, considering that degrowth transitions would also involve profound changes in several other aspects of the convenient-yet-unsustainable Western lifestyle, it seems rather too optimistic to us to hope for an overall increase in subjective wellbeing, at least in the short-term. An introduction of Cuban style food localism, for example, would, all other things being equal, be accompanied by millions of jobs lost in transport, packing, retail, advertising, manufacturing etc. More research is necessary into the complex issue how several current institutions could change at the same time - and its systemic impacts beyond incremental change.

We accompany our conclusion to deprioritize 'happiness' in degrowth research with a plea to simultaneously prioritize the satisfaction of human needs for all human beings now and in future. In other words, we suggest going back to the original Paris declaration which identified the meeting of basic human needs as main objective of 'degrowth' (Research and Degrowth, 2010) and endorse a downscaling of production and consumption even if subjective well-being scores (temporarily) decrease in the rich countries. In fact, the extent to which more than basic needs can be provided in the 'great transformation' necessary to re-embed economy and society into the environment is an empirical question in itself. In theorizing and applying human needs for degrowth purposes we find Doyal and Gough's concept especially attractive due to its systematic 
account of environmental limits and the 'policy-auditing' approach that follows from it. Indeed, comparative in-depth research into Doyal and Gough's eleven 'intermediate needs' and the extent to which these can be met globally and intergenerationally appears to be a promising degrowth research agenda for the years to come.

\section{Acknowledgements}

An earlier draft of this paper was presented at the Fifth International Degrowth Conference in Budapest. Max Koch would like to acknowledge that his research benefited from the funding of FORTE (Sustainable Welfare and Eco-social Policies, 2016-07284) and FORMAS (The New Urban Challenge? Models of Sustainable Welfare in Swedish Metropolitan Cities, 2016-00340).

\section{References}

Alexander, S. (2012) 'The optimal material threshold: Toward an economics of sufficiency', Real-world Economics Review 61: 2-21.

Amate, J. I. and de Molina, M. G. (2013) 'Sustainable de-growth in agriculture and food: an agro-ecological perspective on Spain's agri-food system', Journal of Cleaner Production 38: 2735.

Assiter, A. and Noonan, J. (2007) 'Human needs: A realist perspective', Journal of Critical Realism 6 (2): 173-198.

Badgley, C. Moghtader, J., Quintero, E., Zakem, E., Jahi Chapelli, M., Aviles-Vazquez, K., Samulon, A. and Perfecto, I. (2007) 'Organic agriculture and the global food supply', Renewable Agriculture and Food Systems 22 (2): 86-108.

Boillat, S., Gerber, J-F. and Funes-Monzote, F. R. (2012) 'What economic democracy for degrowth? Some comments on the contribution of socialist models ad Cuban agroecology', Futures 44: 600-607.

Boonstra, W J, and Joosse, S (2013). 'The social dynamics of degrowth', Environmental Values 22 (2): 171-89. 
Buch-Hansen, H (2014) 'Capitalist diversity and degrowth trajectories to steady-state economies', Ecological Economics, 106: 173-179.

D’Alisa, G., Demaria, F. and Kallis, G. (eds) 2014. Degrowth: A Vocabulary for a New Era. London: Routledge.

Daly, H. E. (1991) Steady-state economics. Washington: Island Press.

Davies, W. (2015) The Happiness Industry. How the Government and Big Business Sold Us WellBeing. London: Verso.

Doyal, L. and Gough, I. (1991) A Theory of Human Need. Basingstoke: Macmillan.

Easterlin, R.A. (1974) Does Economic Growth Improve the Human Lot? In: Paul A. David and Melvin W. Reder (eds) Nations and Households in Economic Growth: Essays in Honour of Moses Abramovitz. New York: Academic Press.

Easterlin, R.A., McVey, L.A., Switek, M., Sawangfa, O. and Zweig, J.S. (2010) 'The happinessincome paradox revisited', Proceedings of the National Academy of Sciences 107 (52): 2246322468.

European Commission (2013) Facts and figures on organic agriculture in the European Union, Brussels: European Commission.

FAO (Food and Agriculture Organization of the United Nations) (2002) 'Organic agriculture, environment and food security', edited by Nadia El-Hage Scialabba and Caroline Hattam. Rome: Food and Agriculture Organization of the United Nations.

FAO (2011) The State of Food Insecurity in the World, Rome: Food and Agriculture Organization of the United Nations, Rome.

FAO (2015) The State of Food Insecurity in the World, Rome: Food and Agriculture Organization of the United Nations, Rome.

Foucault, M. (1977) Discipline and Punish: The Birth of the Prison. New York: Pantheon Books.

Fritz, M. and Koch, M. (2016) 'Economic development and prosperity patterns around the world: Structural challenges for a global steady-state economy', Global Environmental Change 38: 4148.

Fromm, E. (1956) The Sane Society. London: Routledge \& Kegan Paul.

Gasper, D. (1996) Needs and Basic Needs. A Clarification of Meanings, Levels and Different Streams of Work. Working Paper Series No. 210. The Hague: Institute of Social Studies.

Georgescu-Roegen, N. (1975) 'Energy and economic myths', Southern Economic Journal 41 (3): 347-381. 
Gerland, P. et al. (2014) 'World population stabilization unlikely this century, Science 46 (6206): 234-237.

Gomiero, T., Pimentel, D. and Paoletti, M.G. (2011) 'Environmental impact of different agricultural management practices: Conventional vs. organic agriculture', Critical Reviews in Plant Sciences 30: 95-124.

Gough, I. (2014) 'Lists and Thresholds: Comparing the Doyal-Gough Theory of Human Need with Nussbaum's Capabilities Approach', in Comin, F. and Nussbaum, M.C. (eds), Capabilities, Gender, Equality. Towards Fundamental Entitlements. Cambridge: Cambridge University Press.

Gough I. (2015) 'Climate change and sustainable welfare: The centrality of human needs', Cambridge Journal of Economics 39: 1-24.

Haas, G., Geier, U., Schulz, D.G. and Köpke, U. (1995) 'Klimarelevanz des Agrarsektors der Bundesrepublik Deutschland: Reduzierung der Emission von Kohlendioxid', Berichte über Landwirtschaft 73: 387-400.

Hirsch, F. (1976) The Social Limits to Growth. Cambridge: Harvard University Press.

Kahneman, D. and Deaton, A. (2010) 'High income improves evaluation of life but not emotional well-being', Proceedings of the National Academy of Sciences 107 (38): 16489-16493.

Kallis, G. (2011) 'In defence of degrowth', Ecological Economics 70 (5): 873-880.

Koch, M. (2012) Capitalism and Climate Change: Theoretical Discussion, Historical Development and Policy Responses. Basingstoke: Palgrave Macmillan.

Koch, M. (2015) 'Capitalism, climate change and degrowth trajectories to a global steady-state economy’, International Critical Thought 5 (4): 439-452.

Koch, M. and Mont, O. (eds) (2016) Sustainability and the Political Economy of Welfare. London: Routledge.

Koch, M. and Buch-Hansen, H. (2016) 'Human Needs, Steady-State Economics and Sustainable Welfare', in Koch, M. and Mont, O. (eds) Sustainability and the Political Economy of Welfare. London: Routledge.

LaSalle, T. and Hepperly, P. (2008) 'Regenerative Organic Farming: A Solution to Global Warming, The Rodale Institute.

Layard, R. (2011) Happiness: Lessons from a New Science. London: Penguin Books.

Matulla, E., Bray, D. and Matulla, C. (2003) 'Gegenüberstellung von konventioneller und ökologischer Landwirtschaft in Schleswig-Holstein’, GKSS Report 2003/6, Geesthacht, Germany. 
Max-Neef, M. (1991) Human Scale Development. Conception, Application and Further Reflections. New York and London: The Apex Press.

O'Neill, D.W. (2015) 'The proximity of nations to a socially sustainable steady-state economy', Journal of Cleaner Production 108: 1213-1231.

O’Neill, J. (2011) 'The Overshadowing of Needs', in Rauschmayer, F., Omann, I. and Frühmann, J. (eds) Sustainable Development. London: Routledge.

Oswald, A., Proto, E. and Srgoi, D. (2008) 'Happiness and productivity', Warwick Economics Research Paper Series N0. 882: University of Warwick.

Ponisio, Lauren C, M'Gonigle, L. K., Mace, K. C., Palomino, J., de Valpine, P., \& Kremen, C (2014) 'Diversification Practices Reduce Organic to Conventional Yield Gap', Proceedings of the Royal Society B: Biological Sciences, 282(1799).

Piketty, T. (2014) Capital in the $21^{\text {st }}$ Century. Cambridge MA: Harvard University Press.

Pimentel, D., Hepperly, P., Hanson, J., Douds, D., and Seidel, R. (2005) 'Environmental, energetic and economic comparisons of organic and conventional farming systems, Bioscience 55 (7): 573-582.

Research and Degrowth (2010) 'Degrowth declaration of the Paris 2008 Conference', Journal of Cleaner Production 18: 523-524.

Rockström, J., Steffen, W., Noone, K., Persson, Å., Chapin, F. S., Lambin, E., Lenton, T.M., Scheffer, M., Folke, C., Schellnhuber, H., Nykvist, B., De Wit, C. A., Hughes, T., van der Leeuw, S., Rodhe, H., Sörlin, S., Snyder, P. K., Costanza, R., Svedin, U., Falkenmark, M., Karlberg, L., Corell, L. V., Fabry, J. Hansen, J., Walker, B., Liverman, D., Richardson, K., Crutzen, P. \& Foley, J. (2009) 'Planetary boundaries: Exploring the safe operating space for humanity', Ecology and Society 14 (2): 32.

Schneider, F., Kallis, G. and Martinez-Alier, J. (2010) 'Crisis or opportunity? Economic degrowth for social equity and ecological sustainability', Journal of Cleaner Production 18: 511518.

Sekulova, F. (2014) 'Happiness', in D’Alisia, G., Demaria, F. and Kallis, G. (eds) Degrowth: A Vocabulary for a New Era. London: Routledge.

Seufert, V., Ramankutty, N. and Foley, J.A. (2012) 'Comparing the yields of organic and conventional agriculture', Nature 485: 229-232.

Soil Association (2009) 'Soil Carbon and Organic Farming. A Review of the Evidence of Agriculture's Potential to combat climate Change'. Bristol: Soil Association. 
Tilman, D. and Clark, M. (2014) 'Global diets link environmental sustainability and human health', Nature 515: 518-522.

Wezel, A., Casagrande, M., Celette, F., Vian, J.-F., Ferrer, A, and Peigné, J. (2014) 'Agroecological practices for sustainable agriculture. A review', Agronomy for Sustainable Development 34 (1): 1-20.

Wirsenius, S., Azar, C. and Berndes, G. (2010) 'How much land is needed for global food production under scenarios of dietary changes and livestock productivity increases in 2030?' Agricultural Systems 103 (9): 621-638.

World Watch Institute (2004) 'Meat. Now, It's Not Personal! But like it or not, meat-eating is becoming a problem for everyone on the planet', World Watch magazine, Juli/August: 12-20. 